Warren, C.R., R.Burton, O.Buchanan and R.V.Birnie. 2016. Limited adoption of biomass energy crops: the role of farmers' identity and farming culture. Journal of Rural Studies 45C: 175-183.

DOI: $10.1016 /$ j.jrurstud.2016.03.017

\title{
Limited adoption of short rotation coppice: the role of farmers' socio-cultural identity in influencing practice
}

\author{
Charles R. Warren ${ }^{\mathrm{a}, *}$, Rob Burton ${ }^{\mathrm{b}}$, Olivia Buchanan ${ }^{\mathrm{a}}$ and Richard V. Birnie ${ }^{\mathrm{c}}$ \\ ${ }^{a}$ Department of Geography and Sustainable Development, University of St Andrews, \\ Fife, KY16 9AL, Scotland. \\ email: crw2@st-andrews.ac.uk \\ ${ }^{\mathrm{b}}$ Centre for Rural Research, University Centre, Dragvoll, N-7491 Trondheim, Norway. \\ email: rob.burton@bygdeforskning.no \\ ${ }^{\mathrm{c}}$ LandForm Research, Alford, Aberdeenshire, AB33 8LB, Scotland. \\ email: richardvbirnie@gmail.com \\ - Corresponding author. Tel.: +44 1334 463934; fax: +44 1334 463949. Email address: \\ crw2@st-andrews.ac.uk (C.R. Warren)
}

\begin{abstract}
UK energy policy promotes biomass energy crops as potentially significant contributors to renewable energy targets, but few farmers have planted these crops. Amongst the many possible explanations for this disconnect between policy ambitions and delivery on the ground, the role of farmers' socio-cultural identity has received little attention. This study focuses on the Lockerbie area in south-west Scotland, a potentially favourable location for perennial energy crops because (i) it is biophysically suitable for short rotation coppice (SRC) willow, and (ii) Britain's first wood-fueled power station provides a significant local market. A survey in 2009 explored farmers' perceptions of SRC willow, and the key reasons why they adopt or reject perennial energy crops. The results show that most farmers regard SRC willow as a financially risky, overly committing and inappropriate crop for their farms. Whilst financial factors are influential, even large potential profits would be insufficient to persuade many farmers to adopt SRC. Non-financial factors related to identity, lifestyle, farming culture and the perceived priority of food production powerfully shape the overwhelmingly negative attitudes of farmers to SRC. These findings suggest that biomass energy policy, especially regarding woody crops like SRC willow, needs to be more precisely tailored to influential social factors such as socio-cultural identity and local producer culture.
\end{abstract}

Key words: Biomass energy; farmer identity; energy policy 


\section{Introduction: biomass in government policies and farmers' minds}

Biomass energy crops are being actively promoted in many countries as a component of policies on climate change mitigation and renewable energy, but uptake by farmers has been limited, notably in the UK (Adams et al., 2011). This suggests that there is a disconnect between energy policy objectives and the stakeholder community.

Successful delivery of any policy involving land use change depends on decisions made by a multitude of individual land managers, the decision-makers who 'stand at the point where abstract policy imperatives collide with concrete realities' (Constable, 2012:xi). Whilst there is an extensive literature investigating UK farmers' resistance towards planting woodlands, and a growing literature addressing many aspects of establishing perennial energy crops on agricultural land, there has been limited study of the role of farmers' socio-cultural identity ${ }^{1}$ in influencing decisions about planting such crops. Here we investigate this dimension using data obtained in 2009 in south-west Scotland concerning one type of perennial energy crop, namely short rotation coppice (SRC).

Scotland has an ambitious statutory target of reducing greenhouse gas emissions by $80 \%$ from 1990 levels by 2050 (Scottish Government, 2011). Biomass could make a significant contribution, potentially supplying $8-11 \%$ of the entire UK's total primary energy demand by 2020 , with energy crops and agricultural residues expected to expand fastest (DfT/DECC/DEFRA, 2012). Consequently, there is strong policy support at both UK and Scottish levels for substantial expansion (DECC, 2009; Scottish Government, 2011), and projections envisage dramatic expansion of energy crops (Howard et al., 2009; DfT/DECC/DEFRA, 2012). For example, one policy-informing scenario envisages the area devoted to energy crops increasing by a factor of 275 , expanding from 8000 ha in 2008 to cover up to 2.2 Mha of arable and pasture land by 2030, with planting rates reaching 150,000 ha/year (E4Tech, 2009). Various incentives such as establishment grants have been available to facilitate expansion (Alexander et al., 2014a). ${ }^{2}$ Given the potential value of perennial energy crops in producing a carbonneutral fuel, and their capacity to offer a wide range of ecosystem services and other benefits (Karp et al., 2009; Rowe et al., 2009; Mola-Yudego et al., 2014), such policy support is likely to increase (Dwyer, 2011). Indeed, Coleby et al. (2012:374) assert that energy crop production is 'set to drive the most extensive changes in land-use in Britain since the 1950s'. The implications of such changes would be far-reaching, including potentially major effects on landscapes, biodiversity, hydrology and the rural economy (Howard et al., 2009; Karp et al., 2009; Dwyer, 2011; Dockerty et al., 2012).

Clearly, if such crops are to fulfil the dramatically expanded role envisaged by policy-makers, large numbers of farmers will need to choose to adopt them.

However, perennial energy crops such as SRC are unfamiliar to most British farmers, not only because of the novel cultivation techniques required but also because in policy terms they sit outside the 'food and farming box' at the interface between agriculture, forestry and energy policies. This introduces additional, unfamiliar risks and uncertainties (Sherrington et al., 2008; Sherrington and Moran, 2010), partly explaining the stark contrast between the official optimism about energy crops (e.g. Scottish Executive, 2007) and the limited areas planted. Whereas the UK Bioenergy 
Strategy envisages that energy crops of all kinds will cover 0.62-2.43 Mha in England \& Wales, the total area planted in the entire UK by 2011 was just $0.01 \mathrm{Mha}$ (DfT/DECC/DEFRA, 2012), with just 6300 ha in Scotland (RESAS, 2011). ${ }^{3}$ Since then, the planted area has actually been declining (Wilson et al., 2014). These planting area figures reveal the real extent of the gulf separating policy-makers' aspirations and land managers' practice

Such policy-stakeholder disconnects are hardly a new phenomenon; policy design often fails to take full account of the characteristics of the relevant actors, as studies of innovation adoption by farmers have shown (White et al., 2009; Sattler and Nagel, 2010; Ma et al., 2012). Two areas of particular relevance to this study which illuminate the nature of this disconnection are (i) the promotion of farm forestry and agroforestry in Scotland, and (ii) the implementation of agri-environmental policies internationally. These are now briefly reviewed.

Increased integration between farming and forestry in Scotland has been encouraged for many decades (Mackay, 1995), but the policies have met with limited success. A key reason for this is that there exists a long-standing antipathy amongst Scottish farmers towards tree planting and management, arising from a deep-seated sense of differentiation between farming and forestry within the respective professional communities (Towers et al., 2006; Warren, 2009, pp.332ff). Despite the many cogent arguments for adopting farm forestry and agroforestry, the persistence of this 'deep cultural divide between farming and forestry' (FCS, 2012: 2) constitutes a significant barrier (Burgess et al., 1999; Morgan-Davies et al., 2003; Sibbald, 2006). Tenant farmers, who farm over a third of Scotland's main agricultural holdings, are especially alienated because owners typically retain control of woodlands (Towers et al., 2006). The failure of policy design to recognise this phenomenon of cultural 'tribalism' has militated against greater integration, and has hindered farmers' adoption of land uses involving tree species.

Secondly, and more broadly, a substantial international literature explores the longstanding discrepancy between agri-environmental policies and farmers' values and motivations (Wilson, 2001; Burton et al., 2008). Numerous barriers have been identified which impede the adoption of sustainable and/or conservation-orientated agricultural practices (Rodriguez et al., 2008; Moon and Cocklin, 2011). Amongst the most common are the characteristics and attitudes of farmers themselves, including an oft-reported reluctance to change (Burton et al., 2008). Policies based on the assumption that the 'right' level of payment will deliver desired outcomes ignore the complex web of factors which influence farmers' decisions, and the fact that farmers' goals usually constitute a mix of economic, social and environmental objectives (Farmar-Bowers and Lane, 2009; Greiner et al., 2009; Miller et al., 2009; Greiner and Gregg, 2011). Farmers tend to be strongly influenced by perceptions of what constitutes 'good farming' amongst their farming peers (Ryan et al., 2003; Burton, 2004a, 2012; Burton et al., 2008; Rodriguez et al., 2008), as well as by a deeply engrained production-orientated mindset (Macgregor and Warren, 2006; Gorton et al., 2008). Farmers are thus not the pure profit maximisers of economic models but are 
influenced by social norms, cultural beliefs, socio-psychological factors, aesthetic judgements and personal values concerning nature, family and community (EdwardsJones, 2006; Rodriguez et al., 2008; Cope et al., 2011).

Because agricultural systems are complex social-ecological systems, the effectiveness of policies and policy instruments will depend upon a sound understanding of the motives and perceptions (including self-perceptions) of farmers who are the key actors (Feola and Binder, 2010; Blackstock et al., 2010). This is particularly relevant when policies are seeking to promote new behaviours such as the growing of non-food crops like trees (Zubair and Garforth, 2006). Thus 'the personal attitude of the single farmer ... is of utmost importance' (Sattler and Nagel, 2010:71) because, notwithstanding the overarching framework of agricultural regulations, incentives and policy aspirations, what actually happens on the ground is the product of decisions by individual farmers (Cope et al., 2011).

Given that land use futures are largely determined by farmers' decisions, policy targets will only be achieved when farmers choose to adopt new practices. Self-evident as this might seem, it is striking that policy formulation and technical assessments of potential tend to ignore it. As Cope et al. (2011:855) observe, policy-makers 'typically focus on biophysical and economic criteria that influence farmers' land use decisions at the expense of "intrinsic" socio-cultural motivations'. The prevailing presumption has been that, if the pricing and support structures are right, farmers will be willing to establish large areas of energy crops. This is exemplified by the UK Renewable Energy Strategy which identifies land availability, crop yields, and waste management as key factors affecting future biomass supplies (E4Tech, 2009) but conspicuously omits any consideration of farmers' willingness to plant energy crops. Consequently, examining the critical linkage between policy aspirations and delivery may help to explain the gulf which currently separates technical assessments of the large potential of energy crops and the small area planted.

One of the suggested explanations for this frequently observed gap is the existence of socio-psychological barriers to adoption created by farmers' perceptions and motivations (Alexander et al., 2014a; Mola-Yudego et al., 2014). While farmers in many countries recognise the potential benefits of perennial energy crops, few seem willing to plant them, even when market conditions are favourable, and a minority are actively hostile (Jensen et al., 2007; Panoutsou, 2008; Bocquého and Jacquet, 2010; Cope et al., 2011; Tate et al., 2012; Villamil et al., 2008, 2012; Lupp et al., 2014). Commonly cited barriers to adoption include lack of established markets and support structures, the risks of being an 'early adopter', and the costs (financial, time) of adopting a new crop. Farmers are especially reluctant to devote prime agricultural land to energy crops, often identifying marginal land as the more appropriate location (Cope et al., 2011).

Studies focusing specifically on SRC systems within the UK have identified a similar range of financial and non-financial factors which inhibit their adoption (Towers et al., 2004, 2006; Sherrington et al., 2008; Sherrington and Moran, 2010; Adams et al., 2011; 
Convery et al., 2012; Wilson et al., 2014). These include worries about the reliability of income, disruption to cash flow, opportunity costs, reduced business flexibility and the challenges of moving from annual crops to perennial crops. The above studies also highlight uncertainties surrounding production costs, potential yields and market prices as factors which make farmers wary, together with concerns about the reaction of neighbouring farmers and local communities. Quite apart from the various nonfinancial disincentives, modelling by Sherrington and Moran (2010) and Alexander et al. (2014b) indicates that SRC willow is financially unattractive for most farm types at present. However, would farmers plant it, even if it were to become financially attractive? Just how do farmers perceive this novel use of farmland and its 'goodness of fit' with contemporary farming culture?

\section{Data collection: location and methods}

This study investigates these questions through a survey of farmers in the Lockerbie area of the Dumfries \& Galloway region in south-west Scotland. It focuses on SRC willow because this is the energy crop best matched to Scottish biophysical conditions, with an estimated 25\% of Scotland suitable for growing it (Towers et al., 2004; RCEP, 2004). Most of this suitable land is currently used for livestock production and arable cropping. SRC willow differs from familiar arable crops, notably in terms of its eventual height $(\leq 6 \mathrm{~m})$, greater rooting depths, perennial nature and in its harvesting cycle and timing (every 3-4 years, in winter). SRC willow production therefore requires different skills and machinery from that needed to grow arable crops.

The specific questions addressed are:

1. What are farmers' perceptions of perennial energy crops, and the reasons for those perceptions?

2. What are the primary perceived barriers to the establishment of energy crops?

3. What factors might facilitate future uptake of these crops?

The Dumfries \& Galloway region was selected for two reasons. Firstly, in biophysical terms it is highly suitable for SRC willow production (Towers et al., 1997). Secondly, Britain's first wood-fueled power station, opened in Lockerbie by E.ON in 2009, represents a significant local market for biomass energy crops. This $£ 90 \mathrm{~m}$ combined heat-and-power plant gives biomass energy a potentially important role in the region. The plant generates $44 \mathrm{MWe}$ (electricity) and $6 \mathrm{MW}$ th (heat), and requires around 480,000 tonnes of wood fuel per annum (E.ON, 2012). The company aims to source $60 \%$ of the fuel from local forests, $20 \%$ from SRC willow (grown within a 60 -mile radius) and a further $20 \%$ from recycled wood fibre. E.ON estimates that the SRC biomass component requires some 4,000 hectares of SRC willow, representing a potentially valuable alternative market for the region's farmers. E.ON (2012) explicitly promotes this potential benefit, stating that its 'long term, low risk energy crop initiative' will benefit local farming. If the plant's wood fuel needs cannot be met locally, fuel will have to be imported, compromising the low-carbon credentials of this flagship development. 
During the summer of 2009, a questionnaire survey $(n=190)$ was undertaken. To maximise sample size and representativeness, three different survey instruments were used: postal, online and face-to-face. For the postal survey, addresses were obtained from publicly available lists of registered farms, including all the main enterprise types in the area, and 47 were sent to farms within a 60-mile radius of Lockerbie. Of these, 28 were returned (60\% response rate). A social network website was used to recruit 90 respondents who then completed the questionnaire online. The face-to-face approach was employed at locations frequented by farmers (local markets, summer agricultural shows, agriculture supply stores). Of the total sample, $15 \%(n=28)$ comprised postal questionnaires, $47 \%(n=90)$ were completed online and $38 \%(n=72)$ were completed face-to-face. The questionnaire itself, summarised in Table 1, was necessarily concise to maximise the response rate; initial experience with a longer version revealed a strong aversion amongst farmers to all but the briefest of surveys, thereby limiting the scope of the quantitative data. In order to obtain more in-depth qualitative insights, respondents were invited to participate in a follow-up interview (postal sub-sample) or to elaborate further on their responses (online and face-to-face). Only two of the postal group chose to be interviewed, but majorities of the other two groups provided some additional qualitative commentary. The age profile of the sample was evenly balanced across three age cohorts $(<31 \mathrm{yr}: 34 \% ; 31-50 \mathrm{yr}: 30 \%$; $>51 \mathrm{yr}: 36 \%)$.

\begin{tabular}{|l|l|}
\hline Section 1 & Demographic, geographic and farm-type information \\
\hline Section 2 & Attitudes towards renewable energy and SRC \\
\hline & - relative importance of food crops and energy crops \\
\hline & - attitudes towards growing SRC to produce renewable energy \\
\hline & - attitudes towards growing SRC in D \& G \\
\hline & - the relative merits of energy crops and wind power in D \& G \\
\hline & - knowledge of SRC production techniques \\
\hline Section 3 & - awareness of the Lockerbie biomass power station \\
\hline & $\begin{array}{l}\text { Economic factors and incentives/disincentives } \\
\text { farming operations }\end{array}$ \\
\hline & $\begin{array}{l}\text { - attraction of establishing SRC with increased profit margins relative to } \\
\text { current farming operations }\end{array}$ \\
\hline & - significance of non-annual income from SRC and pre-payment schemes \\
\hline & - significance of government subsidies as an incentive to establish SRC \\
\hline & - most significant positive and negative attributes of SRC \\
\hline
\end{tabular}

Table 1. A summary of the issues addressed in the questionnaire. Some issues were explored using several questions. SRC $=$ short rotation coppice (here using willow); D \& $\mathrm{G}=$ Dumfries \& Galloway.

\section{Questionnaire results}

This section presents the quantitative results of the questionnaire survey; the qualitative findings are incorporated within the discussion. Farmers' views towards the general concept of growing SRC willow were almost evenly divided between positive (49\%) 
and negative ( $42 \%)$, with the remainder agnostic. However, when asked about introducing willow to their own farms they were predominantly opposed to the idea. Only $15 \%$ thought that it was a 'positive' or 'interesting' proposal whereas $61 \%$ were opposed, the primary reason being a belief that SRC willow is not a suitable crop for farms in the region.

To test the significance of economic factors, farmers were asked a pair of hypothetical questions about the profitability of SRC willow:

1. Would you consider growing willow if profit margins were equivalent to existing operations?

2. Would you consider growing willow if it offered greater profits than current practices?

Some $71 \%$ responded negatively to the first question (similar profitability), with only small minorities saying 'yes' (4\%) or 'maybe' (10\%). All those who said 'yes' were farmers over 50. In response to the second question (increased profitability), more farmers were potentially interested (21\%), but 40\% still answered 'no' (40\%), with a further $24 \%$ answering 'maybe'. Again, the most positive attitudes were found amongst the oldest farmers; the over 50s accounted for two thirds of the 'yes' responses. A follow-up question asked whether an increase in subsidies would encourage them to grow willow; those who believed not (47\%) outnumbered those who believed that it would $(31 \%)$.

Table 2 summarises farmers' responses when asked to identify (i) the single main barrier to SRC production in the region, and (ii) a single factor which might persuade them to establish SRC. The most frequently cited barrier, that willow production is not suitable, relates to farmers' perception of SRC as an arable-type practice which would not easily integrate with the animal husbandry practices which predominate in this largely upland region (see Discussion). This includes the problems anticipated with using harvesting machinery on steep, wet terrain during the winter harvesting season. In the context of the 'inflexibility' barrier, farmers referred to the 'lock-in effect' of the long-term commitment. They contrasted this unfavourably with the opportunity for annual reassessment that is possible with 'normal' farming practices, enabling farmers to respond to commodity price fluctuations. The 'Other' barriers in Table 1 included unfamiliarity with the practice, fears that SRC would reduce land values, high initial capital costs and delayed revenue (typically a four year gap between establishment and first harvest). 


\begin{tabular}{|c|c|c|c|}
\hline A. Barrier & $\%$ & B. Facilitating factor & $\%$ \\
\hline $\begin{array}{l}\text { 1. Not suitable for farming practices } \\
\text { and/or for the land }\end{array}$ & 33 & 1. Profitability & 32 \\
\hline $\begin{array}{l}\text { 2. Inflexibility (crop/roots hard to } \\
\text { remove) }\end{array}$ & 18 & 2. Nothing & 32 \\
\hline 3. Uneconomic/price uncertainty & 13 & 3. Predictable income & 14 \\
\hline 4. Insufficient land available & 11 & 4. Increased understanding & 12 \\
\hline 5. Roots damaging field drainage & 7 & No response & 10 \\
\hline 6. Lack of competitive market & 4 & & \\
\hline 7. Other (see text) & 4 & & \\
\hline No response & 10 & & \\
\hline
\end{tabular}

Table 2. Primary barriers and potential facilitation factors for willow production identified by respondents in the survey.

Column B of Table 1 shows that $46 \%$ of the farmers identified financial issues as potentially the most important facilitation factors ('profitability' and 'predictable income'). When asked specifically whether a pre-payment scheme would facilitate adoption by offsetting the delayed revenue problem, half the respondents believed that it would, while $36 \%$ said that it would not (the remainder being unsure). However, of equal importance to 'profitability' is the $32 \%$ who responded 'nothing'. For these individuals, no foreseeable factor would persuade them to consider planting willow on their farms. Even those who indicated that profitability might persuade them to adopt SRC stated that they would need long-term guarantees of consistently high profitability.

Given the extensive media coverage of E.ON's biomass power station at Lockerbie, and the promotion activities of Renewable Fuels Limited, the company hired by E.ON to persuade local farmers and foresters to enter into wood-supply contracts, it was assumed that all farmers would be well aware of this potential new market. However, the survey revealed that a substantial minority (38\%) were completely unaware of the Lockerbie plant and of E.ON's objective of obtaining a proportion of their fuel from locally-grown willow. Moreover, most farmers (86\%) declared that they knew very little about SRC willow production and were not in a position to make an informed decision. 


\section{Discussion}

\subsection{Farmers' socio-cultural identity and energy crops}

A disconnection between policy aspirations and the effective delivery of policies at 'ground level' has been a leitmotif of the agri-environmental policy sphere since the 1980s, both in Europe and North America. Despite decisive pro-environmental shifts in policy, neither farming practices nor farmers' mental landscapes changed quickly (Wilson, 2001). This stimulated research into the responses of individual actors to policy measures (Burton, 2004a; 2004b). The results reported here further illuminate this phenomenon of policy-stakeholder disconnection, showing that although the promotion of biomass energy - and specifically SRC cropping systems - makes sense from a national perspective, the policy has little 'ground level' traction largely because it ignores the specificities of farmers' practical and socio-cultural realities. Similarly, in Wilson et al.'s (2014) survey of English farmers, just 7\% indicated a willingness to grow SRC willow. Farmers themselves are keenly aware of this disconnection, as exemplified in one farmer's trenchant dismissal of energy crop targets:

Some suit-wearing office boy must have thought that the hill-billy farmers

of Dumfries \& Galloway would just subside, sell half their herds and plant willow.

Suit-wearing as a symbol of the perceived remoteness of policy-makers from the realities of farming life was a recurrent theme:

What the government and other suited people don't see is that for us, it is not all about profit. We love our job and way of life. It is about having that passion for what you do.

Although the many assessments of the potential of biomass energy generally, and of perennial energy crops specifically, have revealed much about biophysical potential and structural constraints (RCEP, 2004; DEFRA, 2005; Scottish Executive, 2007; E4Tech, 2009), the importance of farmers themselves as a critical link in the policy delivery chain has been little studied. The early work of Towers et al. (1997) on the potential for SRC in Scotland did recognize the critical importance of farmer take-up rates to the potential success of biomass energy cropping, but few subsequent studies have explicitly acknowledged farmers' socio-cultural identity and farming culture as influential factors. The qualitative data from this study reveal that the refusal by many farmers to countenance biomass energy crops is closely linked with such factors, including farmers' deep attachment to current farming practices. As in the quotation above, many farmers articulated their passion and love for their chosen way of life, and the extent to which their identity is bound up with it. The following quotations illustrate this further:

'I am a dairy farmer and always will be.'

'This farm has been in my family for generations and hopefully for generations to come. It is a way of life and our passion. We will never change what we do.'

'We would never grow energy crops. [Dairy farming] is a way of life, our way of life.'

'We are livestock farmers, not tree farmers.' 
Closely related to such sentiments was a frequently expressed view that SRC willow would be an alien and inappropriate crop, at odds with farming culture and requiring new knowledge, unfamiliar expertise and novel machinery:

'This is ridiculous! We are livestock farmers. I don't know anything about growing crops, nor do I have the right equipment.'

'Willow just doesn't suit our farming practice.'

'I still think it is silly to suggest that farmers here grow it. We just aren't those type of farmers.'

'I know that my husband and other farmers would never consider doing anything else. This is all they know.'

The strength of this attachment to existing farming culture, and of the antipathy towards adopting SRC, can be explained with reference to a series of studies by Burton (2004a, 2004b, 2008, 2012; Burton et al., 2008) which reveal the way in which established farming activities generate symbolic capital and socio-cultural rewards which are closely bound up with a farmer's identity. So-called 'roadside farming', the ability to 'read' agricultural landscapes for signs of skilled farming, is an important means by which farmers gain satisfaction, status and prestige via the approbation of their peers (Burton, 2012). The cultural capital associated with conventional farming practices and well-established crops is widely recognised and shared, whereas unfamiliar crops cannot confer the symbolic capital acquired through being recognised as a 'good farmer'. Peer-approval is a powerful positive incentive for farmers (Greiner et al., 2009) because a farm is not merely a working landscape but 'the owner's portrait of himself' (Leopold, 1939 in Burton, 2004a:207). Any practice which has little scope for generating this will have limited appeal.

From this, it follows that the absence (as yet) of positive symbolic value attached to energy crops constitutes a barrier to adoption. Consequently, unless or until energy crops become widespread and familiar, the potential for acquiring kudos and cultural capital from such crops will be minimal, militating against adoption. The strength with which novel practices are resisted because of their perceived incompatibility with farmers' socio-cultural identity and values is apparent from statements like the following:

'I would never grow [willow] because it is not what I do.'

'No amount of money would ever encourage me to grow willow because I am a farmer! I can't think of anything more unattractive to grow on my farm.'

Such farmers will not countenance SRC, even if profitable, because it would threaten both their self-image and their standing within their peer group. They attach greater value to the cultural capital generated by current practices than to the potential financial rewards of an alien practice.

The prevailing perception within a regional farming community of what 'farming' means and of what comprises 'good farming' is thus a strong influence on farmers' decisions. This often includes what Ryan et al. (2003:21) have dubbed a 'tidy rural 
aesthetic', the frequently noted cultural preference for orderly farms with parallel 'tramlines' in crops, well-maintained fences and ditches, and evenly-grown crops (Burton, 2004a, 2012; Burton et al., 2008; Sutherland, 2010). New practices which are perceived to make a farm look 'messy' or 'scruffy' (strongly pejorative terms in the farming lexicon) result in a loss of social status, whether these are conservation practices or the introduction of 'outsize' crops such as SRC willow. The comment above about willow being 'unattractive' illustrates this. While SRC looks like many arable crops when young, it develops into a thicket forest up to $6 \mathrm{~m}$ high, conflicting with this 'tidy rural aesthetic'. Concerns about its landscape impact include obstruction of familiar views, changes in landscape quality (due to the crops themselves and/or the attendant infrastruture) and rapid visual changes when harvested (Rowe et al., 2009; Dockerty et al., 2012). While these can be mitigated via sensitive planning and screen planting, there is the risk that such landscape impacts will upset local people. This itself constitutes a further barrier (Convery et al., 2012); a reluctance to cause local offence can be keenly felt by farmers who often have long-established community relationships and value their social networks highly (White et al., 2009). However, this was not identified as a factor by farmers in the present study, and given that both Karp et al. (2009) and Dockerty et al. (2012) report positive or unconcerned public attitudes concerning the visual impacts of SRC, social acceptance might not prove unduly problematic. The key barrier here is the incompatibility of SRC with farmers' sociocultural identity within the farming and local communities.

\subsection{Energy security, food security and tree crops}

Miller et al. (2009) identify climate change, energy security and food security as three of the key drivers of rural land use change in Scotland. These issues intersect in the debates surrounding energy crops, both nationally and internationally (Rowe et al., 2009), creating the so-called 'food, energy and environment trilemma' (Tilman et al., 2009). Within the UK as a whole the more ambitious bioenergy projections appear unrealistic because of the large areas of productive agricultural land that would be needed and the difficult trade-offs that would be required between competing policy priorities (Burgess et al., 2012). However, within Scotland, Miller et al. (2009) suggest that competition for farmland between energy and food production is unlikely to be fierce because biomass energy production will be focused on poor quality land and existing woodland. This highlights one of the frequently cited advantages of perennial energy crops, namely the scope for growing them on low-grade land (Karp et al., 2009).

Such views conflict, however, with this study's findings that upland livestock farmers and dairy farmers regard willow production as fundamentally unappealing and inappropriate for the region, notwithstanding its theoretical suitability (Towers et al., 1997). One farmer observed that 'willow just doesn't suit our farming practice', while another said simply that 'the land has much better uses'. Instead of the south-west of Scotland, farmers pointed to the eastern arable areas as suitable locations for energy crops:

'Willow production needs to be established in an arable farming area. We don't have the right land here.' 
'We aren't arable farmers. ... If you want a farmer to grow your silly

crops, go to Fife!'

Studies elsewhere in Europe have also found a negative relationship between animal production and willingness to adopt SRC, and that cereal farmers are the most likely adopters (Mola-Yudego and Pelkonen, 2008; Panoutsou, 2008). However, prime food production areas such as those in eastern Scotland are most unlikely to be given over to energy production, and may anyway be unsuitable because of exposure and/or droughtiness (Towers et al., 1997). Moreover, SRC would have to compete financially with high-yielding cereal crops in such areas. It appears, then, that farmers of most kinds regard energy crops as being suitable 'somewhere else', not least because of their commitment to producing food.

A strong belief in the priority of food production over energy production is typical amongst farmers, together with a clear sense that 'farmers [are] not foresters' (Burton, 2004a:196; Convery et al., 2012). The respondents in this study strongly endorsed this prioritisation of food over fuel; $85 \%$ of farmers in the questionnaire survey considered food production more important, with some reinforcing this view emphatically:

'[SRC] is useless! Our job is producing food, not fuel.'

'I'm not against it [growing energy crops] but I feel it is far more

important to secure the food supply for this country so we no longer have

to rely on imports'.

'It [growing willow] is not what we do. We produce FOOD!'

These quotations emphasize that food production is a central part of farmers' sociocultural identity; this is their perceived raison d'être. SRC is regarded as a novel practice which is at odds with their self-perception, traditions and priorities. As noted above, one farmer rejects willow dismissively simply 'because I am a farmer', and another because 'we are ... not tree farmers'. This reveals a firm conviction that SRC is incompatible with present conceptions of farming's purpose and culture, and illustrates the persisting strength of the 'tribal' separation between farming and forestry which was discussed in the introduction. Such robust antipathy towards planting tree species on farmland constitutes a significant barrier to farmers' adoption of SRC willow. These findings, in combination with the discussion of farmers' socio-cultural identity, indicate that policies promoting SRC on agricultural land would necessitate a much greater cultural shift than previously recognised. Financial instruments - even set at a generous level - may therefore be insufficient to persuade significant numbers of farmers to establish perennial energy crops, as discussed below.

Although a farming-forestry 'apartheid' is regarded as 'traditional' in upland Britain, today's segregation is actually anomalous, both historically (Smout et al., 2005; Convery et al., 2012) and in the context of continental Europe where silvicultural and agricultural skills typically go hand in hand (Hulbert et al., 1999). As Warren (2009) notes, SRC is not the 'new' crop that it is often perceived as, but an ancient practice being re-imagined to meet contemporary objectives. A cultural rediscovery of these historic linkages could aid the acceptability of energy crops in contemporary rural settings. 
Given that non-arable farmers reject SRC as an 'alien' practice, that farmers of all kinds prioritize food over energy, and that prime arable land is reserved for food production, it becomes hard to see where substantial expansion of SRC might occur in Scotland. This difficulty is exacerbated by the fact that, in addition to energy crops, numerous other policy objectives are also being targeted at intermediate quality land - too many for them all to be accommodated simultaneously - leading Slee et al. (2014) to label this zone the 'squeezed middle'. One frequently suggested solution, noted above, is that energy crops should be grown on 'marginal land'. However, not only is the definition of such land problematic (Shortall, 2013), but large majorities of those who currently farm poorer quality land (mostly livestock farmers) regard these areas as wholly unsuitable for SRC. This lack of interest from livestock farmers is a challenge for policy-makers, as is the tension between policies promoting energy crops and those seeking to avoid 'food $v$. fuel' conflicts. Wilson et al. (2014) come to similar conclusions in England. Finding geographic space for SRC in the UK is apparently simple but finding cultural space is not.

\subsection{The significance of profitability in farmers' decision-making}

A nuanced message concerning profitability emerges from the data. Although economic considerations are influential (Table 1), they are clearly not the determining issue, and the belief that farming is 'not just about profit' was frequently expressed. Nevertheless, in common with other UK studies (Sherrington et al., 2008; Convery et al., 2012), the results indicate that while profit may not be farmers' primary or sole motivation, a strong financial case would still be needed to persuade them to adopt a new production system. The following quotations bear this out:

'The only thing that would make me consider willow would be lots of money and a guarantee for at least 50 years.'

'We need long-term security. If I can be assured that I will make a considerable amount of money every year, then I may consider it, but it is unlikely.'

Adams et al. (2011:1222) report that the profit motive is 'by far the most important driver for farmers'. Thus far, there is not enough confidence in the bioenergy market to encourage farmers to enter it, even when profit margins are attractive, as evidenced by the limited uptake of SRC in the mid-2000s when arable returns were low (Sherrington and Moran, 2010; Convery et al., 2012). Thus the prospect of profitability - in both the short and long term (Adams et al., 2011) - is a necessary but not a sufficient requirement for persuading farmers to adopt an unproven and unfamiliar practice.

Indeed, as the quotations above indicate, some farmers stipulate unrealistic financial prerequisites for considering it, and the questionnaire results show that increased subsidies would only change the attitudes of a minority. In fact, even substantial profits would be insufficient for some, as demonstrated by the statement quoted above that 'no amount of money would ever encourage me to grow willow'. Similarly, Convery et al. (2012) found that gross margins for energy crops would need to be far above mere economic viability to persuade Cumbrian farmers to adopt them. This conclusion concurs with international evidence concerning energy crops (Bocquého and Jacquet, 2010; Cope et al., 2011) and also with the more general finding that while financial 
considerations are important in farmers' decision-making, they may not be paramount (Miller et al., 2009; Sattler and Nagel, 2010; Celio et al., 2014). For many, farming is a vocation and a lifestyle, with profitability being a means to an end, not an end in itself, and farmers often have strong emotional attachments to their land, livestock and farming style, as the results above show. Consequently, their decision-making processes are not limited to business-related factors alone but incorporate 'whole life' considerations (Farmar-Bowers and Lane, 2009). Gross margins alone are poor predictors of uptake (Sherrington and Moran, 2010).

It seems, then, that if growing SRC willow were to become reliably profitable, it might make it a less unattractive option but it would still not be sufficiently appealing to make most farmers adopt it. Older farmers were the only exception, with $42 \%$ of the over-50s indicating a willingness to consider SRC willow if profit margins exceeded those of current practices. It might be expected that younger farmers would be the most open to innovation and that farmers nearing retirement would be resistant to change, and this is, in fact, what is reported by Convery et al. (2012), but the converse applies in this study. Studies in Scotland, Sweden and the USA have also found that older farmers are the demographic most willing to engage in willow production (Rosenqvist et al., 2000; Villamil et al., 2008; Sherrington and Moran, 2010), perhaps due to a desire to reduce daily involvement in farming (Sherrington et al., 2008; Adams et al., 2011). Establishing causal relationships between farmers' demographic characteristics and their decisions is complex (Burton, 2014), but these findings suggest that targeted advocacy could be fruitful in some contexts.

\subsection{Innovation adoption by farmers}

Innovation-diffusion theory has proved a fruitful framework within which to analyse farmers' responses to policy initiatives (Villamil et al., 2008; White et al., 2009; Sattler and Nagel, 2010), utilising the characteristics of innovation identified by Rogers (2003) (Table 3). This framework clarifies the various criteria which guide farmers' responses.

\begin{tabular}{|c|c|}
\hline $\begin{array}{l}\text { Characteristics of } \\
\text { Innovation }\end{array}$ & Description \\
\hline 1. Relative advantage & Degree to which a new practice outperforms an existing practice \\
\hline 2. Compatibility & Consistency with existing practices, values and needs \\
\hline 3. Complexity & Ease of implementation \\
\hline 4. $\quad$ Trialability & Ability to pilot or test the new practice prior to adoption \\
\hline 5. Observability & Ability to observe the innovation in use elsewhere \\
\hline 6. Risk & Degree of perceived risk \\
\hline
\end{tabular}

Table 3. Key characteristics of innovation. After Rogers (2003), who discusses the first five factors, and White et al. (2009) who add 'risk' as a sixth characteristic.

All six factors emerge as components of farmers' reluctance to adopt SRC willow in Dumfries \& Galloway, with the perceived incompatibility of these crops with regional 
farming practices and farmers' socio-cultural identity acting as a significant barrier, as discussed above. Additionally, the perceived risks of committing to a novel crop militate against adoption. Both the quantitative and qualitative results demonstrate that, in the eyes of most farmers, planting SRC willow would be a novel, high-risk venture for which they have no enthusiasm. In one farmer's words:

No high-intensity famer of this day and age could afford to sacrifice large areas of ground for SRC willow, especially on high-yielding soils ... The financial back-up just isn't there to justify it, even on a contract with the guarantee of sale. Biomass is still too high a risk to take.

The importance of compatibility in facilitating adoption of novel practices has frequently been noted (Ryan et al., 2003; Rodriguez et al., 2008; Moon and Cocklin, 2011). Lack of observability is also significant; from this and previous studies (e.g. Convery et al., 2012), it is apparent that most farmers are wary of being 'early adopters'. In terms of relative advantage, the long-term commitment required by energy crops constitutes a significant barrier to adoption, confirming previous research (Sherrington and Moran, 2010; Cope et al., 2011; Wilson et al., 2014). More broadly, the results support studies investigating the diffusion of renewable energy technologies which have found that the systemic character of innovations, and not simply market failure, is a key factor explaining their slow adoption (Negro et al., 2012). This reinforces the point made above that adoption is strongly influenced by considerations other than financial benefit.

Overall, it is clear that any policy which requires farmers to adopt innovative practices is unlikely to succeed without taking full account of their motivations and socio-cultural characteristics, and how these influence their decision-making. The experience of SRC, in the UK and overseas, emphasizes that farmers' perspectives and goals differ significantly from those of policy-makers and government agencies (Villamil et al., 2008). Consequently, if policies are to be successful and socially acceptable, they need to be co-developed with the actors and stakeholders involved. To borrow the terminology of the farmers in this study, 'the suits' need to develop more understanding of 'the boilersuits'.

\section{Conclusions}

This study presents evidence that farmers' decisions about adopting innovative practices are strongly affected by psycho-social and cultural factors. Farmers in south-west Scotland are not opposed in principle to the concept of SRC willow production. They do, however, express strong antipathy towards establishing SRC themselves, perceiving such an innovation as incompatible with current practices, alien to their way of life and a risky, long-term commitment. This reinforces the conclusions of Adams et al. (2012:408) that farmers' perceptions 'play an essential part in adoption decisions and must be taken into consideration' in policy development. The findings presented here help to explain why the policy vision of SRC being widely established on farmland is not yet being realised, and, indeed, why planting rates more recently have been declining (Wilson et al., 2014). They thus not only provide a 'reality check' but also highlight the importance of stakeholder engagement in the design and delivery of policy. Although this survey was carried out in 2009 , there has been no indication in 
subsequent studies (e.g. Convery et al., 2012) that farmers' attitudes are becoming more positive. Some of the basic failings of policy implementation revealed in this survey (e.g. poor marketing and information provision) could easily be remedied, but even in the Lockerbie area where the E.ON power station represents a reliable local market, farmers see willow as irrelevant and unappealing. A parallel story has unfolded at the Sembcorp plant in north-east England where only 5\% of the planned locally-grown area of SRC has been planted (Prag, 2012), and it is echoed in other countries (WolbertHaverkamp and Musshoff, 2014). A combination of farmer resistance, non-availability of appropriate land and financial uncertainty seems set to maintain SRC as a marginal activity.

A key conclusion of this study is that policy design needs to be more precisely tailored to the motivations, viewpoints and risk perceptions of the target audience. Similar conclusions have been reached in other studies concerning energy crops (White et al., 2009; Tate et al., 2012) and in several related areas (e.g. agri-environmental policies (Greiner et al., 2009); agroforestry (Sibbald, 2006); forest conservation programmes (Ma et al., 2012)). However, the lessons from such studies are not commonly used to inform policy-making processes (Greiner and Gregg, 2011; Moon and Cocklin, 2011). Certainly the UK policies promoting perennial energy crops have thus far been perceived as largely irrelevant and unattractive by most farrmers. It is important to note that farmers are a heterogeneous group, as recognised by farmer typologies (Miller et $a l ., 2009)$, and so no incentive or policy design will be equally persuasive for all. Furthermore, the effectiveness of monetary incentives is reduced by the high value attached to non-financial motivations. Economic factors, while important, are not necessarily sufficient in themselves to initiate agricultural diversification into unfamiliar crops. This reinforces the need to understand the values and goals of 'policy deliverers' so that the disconnection between them and policy-makers can be reduced, thereby enhancing policy delivery. Policies for land-based renewable energy technologies would therefore benefit from incorporating the insights of social scientific research into the socio-cultural context. This could enable energy crops to realize their significant potential to contribute to emissions reduction and energy security. 


\section{References}

Adams, P.W., Hammond, G.P., McManus, M.C., Mezzullo, W.G. 2011. Barriers to and drivers for UK bioenergy development. Renew. Sust. Energy Revs. 15, 1217-1227.

Alexander, P., Moran, D., Rounsevell, M.D.A., Hillier, J., Smith, P. 2014a. Cost and potential of carbon abatement from the UK perennial energy crop market. Glob. Change Biol. Bioenergy 6(2), 156-168.

Alexander, P., Moran, D., Smith, P. and 9 others. 2014b. Estimating UK perennial energy crop supply using farm-scale models with spatially disaggregated data. Glob. Change Biol. Bioenergy 6(2), 142-155.

Blackstock, K.L., Ingram, J., Burton, R., Brown, K.M., Slee, B. 2009. Understanding and influencing behaviour change by farmers to improve water quality. Sci. Total Env. 408, 5631-5638.

Bocquého, G., Jacquet, F. 2010. The adoption of switchgrass and miscanthus by farmers: impact of liquidity constraints and risk preferences. Energy Pol. 38, 2598-2607.

Burgess, P.J., Brierley, E.D.R., Morris, J., Evans, J. (Eds.). 1999. Farm woodlands for the future. BIOS Scientific, Oxford, $194 \mathrm{pp}$.

Burgess, P.J., Casado, M.R., Gavu, J., Mead, A., Cockerill T., Lord, R., van der Horst, D., Howard, D.C. 2012. A framework for reviewing the trade-offs between renewable energy, food, feed and wood production at a local level. Renew. Sust. Energy Revs. 16, 129-142.

Burton, R.J.F. 2004a. Seeing through the 'good farmer's' eyes: towards developing an understanding of the social symboloic value of 'productivitst' behaviour. Sociol. Ruralis 44, 195-215.

Burton, R.J.F. 2004b. Reconceptualizing the "behavioural approach" in agricultural studies: a socio-psychological perspective. J. Rural Stud. 20, 359-371.

Burton, R.J.F. 2012. Understanding farmers' aesthetic preference for tidy agricultural landscapes: a Bourdieusian perspective. Landscape Res. 37, 51-71.

Burton, R.J.F. 2014. The influence of farmer demographic characteristics on environmental behaviour: a review. J. Env. Manag. 135: 19-26.

Burton, R.J.F., Kuczera, C., Schwarz, G. 2008. Exploring farmers' cultural resistance to voluntary agri-environmental schemes. Sociol. Ruralis. 48, 16-37.

Celio, E., Flint, C., Schoch, P. and Grêt-Regamey, A. 2014. Farmers' perception of their decision-making in relation to policy schemes: a comparison of case studies from Switzerland and the United States. Land Use Pol. 41: 163-171.

Coleby, A.M., van der Horst, D., Hubacek, K., Goodier, C., Burgess, P.J., Graves, A., Lord, R., Howard, D. 2012. Environmental Impact Assessment, ecosystems services and the case of energy crops in England. J. Env. Plan. Mangmt. 55, 369-385.

Constable, J. 2012. Foreword. In: Prag, P., Renewable Energy in the Countryside. $3^{\text {rd }}$ edition. Routledge, Abingdon, pp. iii-xi.

Convery, I., Robson, D., Ottitsch, A., Long, M. 2012. The willingness of farmers to engage with bioenergy and woody biomass production: a regional case study from Cumbria. Energy Pol. 40, 293-300.

Cope, M.A., McLafferty, S., Rhoads, B.L. 2011. Farmer attitudes toward production of perennial energy grasses in east central Illinois: implications for community-based decision making. Ann. Ass. Am. Geog. 101, 852-862.

DECC. 2009. The UK Renewable Energy Strategy. Department of Energy and Climate Change, London.

DfT/DECC/DEFRA. 2012. UK Biomass Strategy. Department for Transport, Department of Energy and Climate Change, and Department for Environment, Food and Rural Affairs. Available at: http://www.decc.gov.uk/assets/decc/11/meeting-energy-demand/bioenergy/5142-bioenergy-strategy-.pdf (Accessed November 2012) 
DEFRA. 2005. Biomass Task Force: report to Government. Department for Environment, Food and Rural Affairs, London.

Dockerty, T., Appleton, K. and Lovett, A. 2012. Public opinion on energy crops in the landscape: considerations for the expansion of renewable energy from biomass. J. Env. Plan. Mangmt. 55(9): 1134-1158.

Dwyer, J. 2011. UK land use futures: policy influence and challenges for the coming decades. Land Use Pol. 28, 674-683.

E4Tech, 2009. Biomass supply curves for the UK. Available at: http://www.e4tech.com/en/overview-publications.cfm (Accessed June 2012)

E.ON. 2012. Steven's Croft site statistics. Available at: www.eonuk.com/generation/stevenscroft.aspx (Accessed November 2011)

Edwards-Jones, G. 2006. Modelling farmer decision-making: concepts, progress and challenges. Animal Sci. 82, 783-790.

Farmar-Bowers, Q., Lane, R. 2009. Understanding farmers' strategic decision-making processes and the implications for biodiversity conservation policy. J. Env. Managmt. 90, 1135-1144.

FCS. 2012. Report of the Woodland Expansion Advisory Group. Forestry Commision Scotland, Edinburgh. Available at: http://www.forestry.gov.uk/weag (Accessed August 2012).

Feola, G., Binder, C.R. 2010. Towards an improved understanding of farmers' behaviour: the integrative agent-centred (IAC) framework. Ecol. Econ. 69, 2323-2333.

Gorton, M., Douarin, E., Davidova, S., Latruffe, L. 2008. Attitudes to agricultural policy and farming futures in the context of the 2003 CAP reform: a comparison of farmers in selected, established and new Member States. J. Rural Stud. 24, 322-336.

Greiner, R., Gregg, D. 2011. Farmers' intrinsic motivations, barriers to the adoption of conservation practices and effectiveness of policy instruments: empirical evidence from northern Australia. Land Use Pol. 28, 257-265.

Greiner, R., Patterson, L., Miller, O. 2009. Motivations, risk perceptions and adoption of conservation practices by farmers. Agric. Syst. 99, 86-104.

Howard, D.C., Wadsworth, R.A., Whitaker, J.W., Hughes, N., Bunce, R.G.H. 2009. The impact of sustainable energy production on land use in Britain through to 2050. Land Use Pol. 26S, S284-S292.

Hulbert, I., Waterhouse, T., Gordon, P., Morgan-Davies, C. 1999. Silvo-pastoralism for the uplands of Scotland - a new approach to an old problem: the integration of farming and forestry. Scot. For. 53, 231-235.

Jensen, K., Clark, C.D., Ellis, P., English, B., Menard, J., Walsh, M. 2007. Farmer willingness to grow switchgrass for energy production. Biom. Bioenergy 31, 773-781.

Karp, A., Haughton, A.J., Bohan, D.A., Lovett, A.A., Bond, A.J., Dockerty, T., Sunnenberg, G., Finch, J.W., Sage, R.B., Appleton, K.J., Riche, B., Mallott, M.D., Mallott, V.E.,

Cunningham, M.D., Clark, S.J., Turner, M.M. 2009. Perennial energy crops: implications and potential. In: Winter, M. and Lobley, M. (Eds.), What is land for? The food, fuel and climate change debate. Earthscan, London, pp. 47-72.

Lupp, G., Bastian, O., Steinhauser, R., Syrbe, R-U. 2014. Perceptions of energy crop production by lay people and farmers using the ecosystem approach. Moravian Geogr. Reps. 22, 15-24.

Ma, Z., Butler, B.J., Kittredge, D.B., Catanzaro, P. 2012. Factors associated with landowner involvement in forest conservation programs in the U.S.: implications for policy design and outreach. Land Use Pol. 29, 53-61. 
Macgregor, C.J., Warren, C.R. 2006. Adopting sustainable farm management practices within Nitrate Vulnerable Zones in Scotland: the view from the farm. Agric. Ecosyst. Env. 113, 108-119.

Mackay, D. 1995. Scotland's rural land agencies. Scottish Cultural Press, Aberdeen, 227 pp.

Miller, D., Sutherland, L.A., Morrice, J., Aspinall, R., Barnes, A., Blackstock, K., Schwarz, G., Buchan, K., Donnelly, D., Hawes, C., McCrum, G., McKenzie, B., Matthews, K., Miller, D., Renwick, A., Smith, M., Squire, G., Toma, L. 2009. Changing land use in rural Scotland - drivers and decision making. Rural Land Use Study Project 1. The Scottish Government, Edinburgh.

Mola-Yudego, B., Pelkonen, P. 2008. The effects of policy incentives in the adoption of willow short rotation coppice for bioenergy in Sweden. Energy Pol. 36, 3062-3068.

Mola-Yudego, B, Dimitriou, I., Gonzalez-Garcia, S., Gritten, D., Aronsson, P. 2014. A conceptual framework for the introduction of energy crops. Renew. Energy 72: 29-38.

Moon, K., Cocklin, C. 2011. Participation in biodiversity conservation: motivations and barriers of Australian landholders. J.Rural Stud. 27, 331-342.

Morgan-Davies, C., Waterhouse, T., Holland, J., Zografos, C. 2003. Assessing uptake of innovative hill land use. Scot. For. 57, 211-215.

Negro, S.O., Alkemade, F., Hekkert, M.P. 2012. Why does renewable energy diffuse so slowly? A review of innovation system problems. Renew. Sust. Energy Revs. 16, 38363846.

Panoutsou, C. 2008. Bioenergy in Greece: policies, diffusion framework and stakeholder interactions. Energy Pol. 36, 3674-3685.

Prag, P. 2012. Renewable Energy in the Countryside. $3^{\text {rd }}$ Ed. Routledge, Abingdon.

RCEP. 2004. Biomass as a Renewable Energy Source. Royal Commission on Environmental Pollution, London.

RESAS. 2011. Personal communication from Rural and Environment Science and Analytical Services, Scottish Government, 28-10-2011.

Rodriguez, J., Molnar, J., Fazio, R., Sydnor, E., Lowe, M. 2008. Barrers to adoption of sustainable agriculture practices: change agent perspectives. Renew. Agric. Food Syst. 24, 297-308.

Rogers, E.M. 2003. Diffusion of Innovations. $5^{\text {th }}$ Ed. The Free Press, New York.

Rosenqvist, H., Roos, A., Ling, E., Hektor, B. 2000. Willow growers in Sweden. Biom. Bioenergy 18, 137-145.

Rowe, R.L., Street, N.R., Taylor, G. 2009. Identifying potential environmental impacts of large-scale deployment of dedicated bioenergy crops in the UK. Renew. Sust. Energy Revs. 13, 271-290.

Ryan, R.L., Erickson, D.L., De Young, R. 2003. Farmers' motivations for adopting conservation practices along riparian zones in a mid-western agricultural watershed. J. Env. Plan. Managmt. 46, 19-37.

Sattler, C., Nagel, U.J. 2010. Factors affecting farmers' acceptance of conservation measures a case study from north-eastern Germany. Land Use Pol. 27, 70-77.

Scottish Executive. 2007. A Biomass Action Plan for Scotland. Scottish Executive, Edinburgh.

Scottish Government. 2011. 2020 Routemap for Renewable Energy in Scotland. Scottish Government, Edinburgh.

Sherrington, C., Moran, D. 2010. Modelling farmer uptake of perennial energy crops in the UK. Energy Pol. 38, 3567-3578.

Sherrington, C., Bartley, J., Moran, D. 2008. Farm-level constraints on the domestic supply of perennial energy crops in the UK. Energy Pol. 36, 2504-2512. 
Shortall, O.K. 2013. 'Marginal land' for energy crops: exploring definitions and embedded assumptions. Energy Pol. 62: 19-27.

Sibbald, A.R. 2006. Silvopastoral agroforestry: a land use for the future. Scot. For. 60, 4-7.

Smout, T.C., MacDonald, A.R., Watson, F. 2005. A History of the Native Woodlands of Scotland, 1500-1920. Edinburgh University Press, Edinburgh.

Sutherland, L-A. 2010. Environmental grants and regulations in strategic farm business decision-making: a case study of attitudinal behaviour in Scotland. Land Use Pol. 27, 415423.

Tate, G., Mbzibain, A. and Ali, S. 2012. A comparison of the drivers influencing farmers' adoption of enterprises associated with renewable energy. Energy Pol. 49:400-409.

Towers, W., Morrice, J.G., Birnie, R.V., Dagnall, S., Aspinall, R.J. 1997. Assessing the potential for short rotation coppice in Scotland. Scottish Office Agriculture, Environment and Food Department, Edinburgh.

Towers, W., Birnie, R.V., Booth, E., Walker, K., Howes, P. 2004. Energy from crops, timber and agricultural residue. Scottish Executive Environment and Rural Affairs Department, Edinburgh, Executive Report and Technical Annex.

Towers, W., Schwarz, G., Burton, R., Ray, D., Sing, L., Birnie, R.V. 2006. Possible opportunities for future forestry development in Scotland: a scoping study. Forestry Commission Scotland, Edinburgh.

Villamil, M.B., Silvis, A.H., Bollero, G.A. 2008. Potential miscanthus' adoption in Illinois: information needs and preferred information channels. Biom. Bioenergy 32, 1338-1348.

Villamil, M.B., Alexander, M., Silvis, A.H., Gray, M.E. 2012. Producer perceptions and information needs regarding their adoption of bioenergy crops. Renew. Sust. Energy Revs. $16,3604-3612$.

Warren, C.R. 2009. Managing Scotland's Environment. $2^{\text {nd }}$ Ed. Edinburgh University Press, Edinburgh.

White, S.S., Brown, J.C., Gibson, J., Hanley, E., Earnhardt, D. 2009. Planting food or fuel: an interdisciplinary approach to understanding farmers' decision to grow second-generation biofuel feedstock crops. Compar. Technol. Transf. Soc. 7, 287-302.

Wilson, G.A. 2001. From productivism to post-productivism ... and back again: exploring the (un)changed natural and mental landscapes of European agriculture. Trans. Inst. Brit. Geog. 26, 77-102.

Wilson, P., Glithero, N.J. and Ramsden, S.J. 2014. Prospects for dedicated energy crop production and attitudes towards agricultural straw use: the case of livestock farmers. Energy Pol. 74: 101-110.

Wolbert-Haverkamp, M. and Musshoff, O. 2014. Are short rotation coppices an economically interesting form of land use? A real options analysis. Land Use Pol. 38: 163-174.

Zubair, M., Garforth, C. 2006. Farm level tree planting in Pakistan: the role of farmers' perceptions and attitudes. Agrofor. Syst. 66, 217-229. 


\section{Footnotes}

1. A person's socio-cultural identity is their self-conception and self-perception as part of a social group that has its own distinct culture.

2. At the time of this study, support for SRC crops of willow or poplar was available under Axis 1 of the European Commission Regulation EC 1698/2005 with the explicit intention of aiding farm diversification and carbon sequestration. A contribution to costs up to a maximum of $£ 1000 /$ ha was offered, subject to the planting of a minimum area of 2 ha at a minimum stocking density of 10,000 cuttings/ha for a minimum period of 5 years. Separately, under the banded Renewables Obligation, electricity generation from energy crops is supported at a higher level than regular biomass.

3. This figure covers the 33,600 larger holdings ( $\geq 1 \mathrm{ha}$ ) only, and so slightly underestimates the total area of SRC on all farms in Scotland (52,300 holdings).

4. Boilersuits are working clothes commonly worn by British farmers. 